\title{
Plasma exchange successfully treats central pontine myelinolysis after acute hypernatremia from intravenous sodium bicarbonate therapy
}

Kyung Yoon Chang, In-Hee Lee, Gi Jun Kim, Kangwon Cho, Hoon Suk Park and Hyung Wook Kim*

\begin{abstract}
Background: Osmotic demyelination syndrome (ODS) primarily occurs after rapid correction of severe hyponatremia. There are no proven effective therapies for ODS, but we describe the first case showing the successful treatment of central pontine myelinolysis (CPM) by plasma exchange, which occurred after rapid development of hypernatremia from intravenous sodium bicarbonate therapy.
\end{abstract}

Case presentation: A 40-year-old woman presented with general weakness, hypokalemia, and metabolic acidosis. The patient was treated with oral and intravenous potassium chloride, along with intravenous sodium bicarbonate. Although her bicarbonate deficit was $365 \mathrm{mEq}$, we treated her with an overdose of intravenous sodium bicarbonate, $480 \mathrm{mEq}$ for 24 hours, due to the severity of her acidemia and her altered mental status. The next day, she developed hypernatremia with serum sodium levels rising from $142.8 \mathrm{mEq} / \mathrm{L}$ to $172.8 \mathrm{mEq} / \mathrm{L}$. Six days after developing hypernatremia, she exhibited tetraparesis, drooling, difficulty swallowing, and dysarthria, and a brain MRI revealed high signal intensity in the central pons with sparing of the peripheral portion, suggesting CPM. We diagnosed her with CPM associated with the rapid development of hypernatremia after intravenous sodium bicarbonate therapy and treated her with plasma exchange. After two consecutive plasma exchange sessions, her neurologic symptoms were markedly improved except for mild diplopia. After the plasma exchange sessions, we examined the patient to determine the reason for her symptoms upon presentation to the hospital. She had normal anion gap metabolic acidosis, low blood bicarbonate levels, a urine pH of 6.5, and a calyceal stone in her left kidney. We performed a sodium bicarbonate loading test and diagnosed distal renal tubular acidosis (RTA). We also found that she had Sjögren's syndrome after a positive screen for anti-Lo, anti-Ra, and after the results of Schirmer's test and a lower lip biopsy. She was discharged and treated as an outpatient with oral sodium bicarbonate and potassium chloride.

Conclusion: This case indicates that serum sodium concentrations should be carefully monitored in patients with distal RTA receiving intravenous sodium bicarbonate therapy. We should keep in mind that acute hypernatremia and CPM can be associated with intravenous sodium bicarbonate therapy, and that CPM due to acute hypernatremia may be effectively treated with plasma exchange.

Keywords: Central pontine myelinolysis, Hypernatremia, Plasma exchange, Renal tubular acidosis, Sjögren's syndrome, Sodium bicarbonate

\footnotetext{
* Correspondence: khw@catholic.ac.kr

Division of Nephrology, Department of Internal Medicine, St. Vincent's

Hospital, The Catholic University of Korea, Seoul, Korea
} 


\section{Background}

Osmotic demyelination syndrome (ODS), which is also known as central pontine myelinolysis (CPM) or extrapontine myelinolysis, primarily occurs after the rapid correction of severe hyponatremia. The clinical manifestations of ODS are typically delayed for two to six days after swift elevations in the serum sodium level. The symptoms, which are often irreversible or only partially reversible, include dysarthria, dysphagia, tetraparesis, behavioral disturbances, lethargy, confusion, disorientation, and coma [1]. ODS can also occur during other osmotic challenges such as rapid correction of hypernatremia [2] and the development of acute hypernatremia from normal sodium concentrations $[3,4]$.

When CPM is associated with the rapid correction of hyponatremia, plasma exchange (plasmapheresis) can be a beneficial therapy. In fact, $\mathrm{Bibl}$ et al. reported that three young female patients with CPM, which associated with correction of hyponatremia, were successfully treated with extensive therapeutic plasma exchange [5]. However, ours is the first case report of CPM after rapid development of hypernatremia from sodium bicarbonate therapy to be successfully treated by plasma exchange.

\section{Case presentation}

A 40-year-old woman presented with general weakness, nausea, vomiting, numbness, and weight loss of $8 \mathrm{~kg}$ over the previous two months. The patient was $154 \mathrm{~cm}$ tall and weighed $57 \mathrm{~kg}$. Her blood pressure was 100/60 mmHg and pulse was 110 beats/min. She was on no diuretics or other medications. She did not have a medical history or diarrhea upon presentation. On admission, she had weakness in both limbs (Medical Research Council Grade 2), but her deep-tendon reflexes were intact. Babinski's sign and ankle clonus were absent.

Upon initial laboratory analysis, her sodium was $142.8 \mathrm{mEq} / \mathrm{L}$; potassium, $2.3 \mathrm{mEq} / \mathrm{L}$; chloride, $125.5 \mathrm{mEq} /$ $\mathrm{L}$; calcium, $7.7 \mathrm{mg} / \mathrm{dL}$; phosphorus, $1.1 \mathrm{mg} / \mathrm{dL}$; magnesium, $2.6 \mathrm{mg} / \mathrm{dL}$; blood urea nitrogen, $17.7 \mathrm{mg} / \mathrm{dL}$; creatinine, $1.0 \mathrm{mg} / \mathrm{dL}$; and albumin, $4.2 \mathrm{~g} / \mathrm{dL}$. Her spot urine potassium was $16.9 \mathrm{mEq} / \mathrm{L}$, and the transtubular potassium gradient (TTKG) was 7\%, suggesting renal loss. Blood gas analysis revealed a $\mathrm{pH}$ of 7.194, $\mathrm{PCO}_{2}$ of $19.5 \mathrm{mmHg}, \mathrm{PO}_{2}$ of $67.8 \mathrm{mmHg}, \mathrm{HCO}_{3}$ of $7.6 \mathrm{mEq} / \mathrm{L}$, $\mathrm{SpO}_{2}$ of $90.2 \%$, and a serum anion gap of 9.7, suggesting normal anion gap metabolic acidosis. Urinalysis revealed a $\mathrm{pH}$ of 6.5 and a urine anion gap of 6.1.

Due to the patient's hypotension and altered mental status, she was admitted to the intensive care unit. She required mechanical ventilatory support with supplemental oxygen due to lethargy, somnolence, and respiratory failure $\left(\mathrm{PCO}_{2} 45.3 \mathrm{mmHg}\right)$. She was treated with intravenous potassium chloride and an oral potassium chloride tablet via nasogastric tube.
In addition to ventilatory support, she also required treatment for her severe acidemia with sodium bicarbonate. Her desired bicarbonate level was $24 \mathrm{mEq}$, and her bicarbonate deficit was calculated to be $365 \mathrm{mEq}$ from the following formula: bicarbonate deficit $=(0.5 \times$ lean body weight $\times(24-$ serum bicarbonate) [6]. Her lean body weight was calculated to be $44.5 \mathrm{~kg}$ from the following formula: lean body weight $[\mathrm{kg}]=9270 \times$ body weight $[\mathrm{kg}] /$ $6680+\left(216 \times\right.$ BMI $\left.\left[\mathrm{kg} / \mathrm{m}^{2}\right]\right)$. We treated her with an overdose of $480 \mathrm{mEq}$ of intravenous sodium bicarbonate in 5\% dextrose and water solution because her mental status and severe metabolic acidosis did not improve. The next day, her potassium was corrected to normal levels $(4.2 \mathrm{mEq} / \mathrm{L})$. However, we found acute hypernatremia with her sodium levels rising from $142.8 \mathrm{mEq} / \mathrm{L}$ to $172.8 \mathrm{mEq} / \mathrm{L}$. We began treating her with half-normal saline and $5 \%$ dextrose in water, and her serum sodium level gradually decreased from $172.8 \mathrm{mEq} / \mathrm{L}$ to $148.0 \mathrm{mEq} / \mathrm{L}$ over the course of six days (Figure 1). As her hypernatremia was corrected, she became more alert and her weakness was greatly improved.

Six days after the development of hypernatremia, several other symptoms became evident including dysarthria, drooling, difficulty swallowing, and tetraparesis. Because of these symptoms, we suspected ODS associated with acute hypernatremia. Consistent with our clinical suspicion, a brain MRI revealed symmetric, high-intensity signal in the central pons with sparing of the peripheral portion, suggesting CPM (Figure 2). Soon after this diagnostic confirmation of CPM, two consecutive therapeutic plasma exchange sessions for two days were started with a total of $4394 \mathrm{~mL}$ plasma exchanged with albumin 5\%, crystalloids, and fresh frozen plasma. The day following the plasma exchange, she regained speech and became oriented. Her neurological symptoms, which included dysarthria, difficulty swallowing, and tetraparesis, were markedly improved, but mild diplopia was present.

After the patient was stabilized, we were able to work her up to explore the primary cause of her presenting symptoms. We suspected distal renal tubular acidosis (RTA) due to the normal anion gap metabolic acidosis, a serum bicarbonate level $<10$, hypokalemia, and urine $\mathrm{pH}$ of 6.5 (> 5.5), and due to the presence of a calyceal stone in her left kidney. We performed a sodium bicarbonate $\left(\mathrm{NaHCO}_{3}\right)$ loading test to confirm distal RTA [7]. In $\mathrm{NaHCO}_{3}$ loading test, $8.4 \% \mathrm{NaHCO}_{3}$ solution was infused intravenously at a rate of $57 \mathrm{mEq} /$ hour $(1 \mathrm{mEq} / \mathrm{kg} / \mathrm{hour})$. Urine and blood samples were taken at 1-hour intervals and urine and blood $\mathrm{PCO}_{2}$ were measured using a blood gas analyzer. When the urine $\mathrm{pH}$ was raised to 7.6, urine $\mathrm{PCO}_{2}$, blood $\mathrm{PCO}_{2}$, urine $\mathrm{HCO}_{3}$, blood $\mathrm{HCO}_{3}$, urine creatinine and serum creatinine were $44.5 \mathrm{mmHg}$, $34.8 \mathrm{mmHg}, 40.1 \mathrm{mEq} / \mathrm{L}, 25.8 \mathrm{mEq} / \mathrm{L}, 64.5 \mathrm{mg} / \mathrm{dL}$, and $0.7 \mathrm{mg} / \mathrm{dL}$, respectively. The results of $\mathrm{NaHCO}_{3}$ loading 


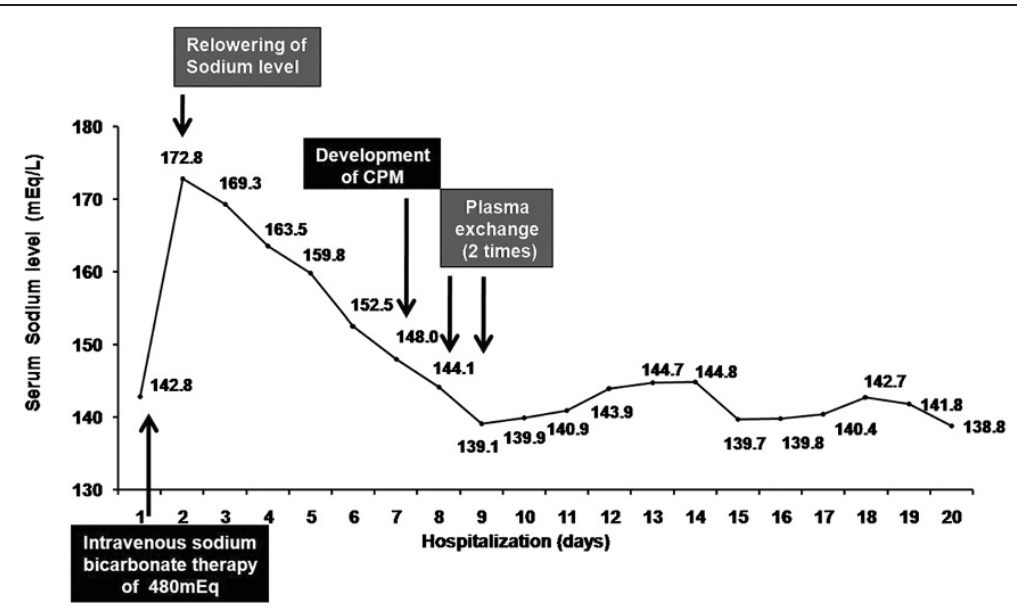

Figure 1 Sodium level changes.

test revealed a fractionated excretion of $\mathrm{HCO}_{3}$ of $1.68 \%$ and the urine-to-blood carbon dioxide tension gradient $\left(\mathrm{U}-\mathrm{B} \mathrm{PCO}_{2}\right.$ ) of 9.7 , suggesting distal RTA. In addition to the distal RTA, we also found that she had Sjögren's syndrome after the results of Schirmer's test and after she screened positive for anti-Lo and anti-Ra, which was confirmed by a salivary scan and lower lip biopsy. She was discharged and treated at an outpatient clinic with oral sodium bicarbonate and potassium chloride. After one year of follow-up, her neurological symptoms were improved, but mild diplopia remained.

\section{Discussion}

Hypernatremia is defined as a serum sodium concentration above $145 \mathrm{mEq} / \mathrm{L}$, and it is most often caused by water loss from the gastrointestinal tract due to vomiting or diarrhea, water loss from the skin by sweating, or loss in the urine due to diabetes insipidus, administration of diuretics, recovery from renal failure, or glucosuria. Less commonly, hypernatremia results from the administration of salt in excess of water, such as after intravenous administration of hypertonic saline and salt tablets [8]. In addition, it may occur with the use of certain drugs, such as lithium and valproate $[9,10]$, and it has also been shown to occur in patients treated with excess sodium bicarbonate to correct metabolic acidosis [11]. In this case, acute hypernatremia resulted from intravenous sodium bicarbonate therapy for the treatment of severe metabolic acidosis and altered mental status in a patient with symptomatic distal RTA and Sjögren's syndrome.

Osmotic disturbances like rapid correction of hyponatremia can be associated with demyelination of the pons, causing CPM. The disruption of blood brain barrier (BBB) occur secondary to osmotic stress and is thought to be one of the leading factors in pathogenesis of CPM. In fact, in a murine experiment, BBB disruption during the first 24 hours of hyponatremia was associated with a $70 \%$ risk of demyelination [12]. CPM can occur in the setting of several osmotic challenges. First, rapid and excessive correction of sodium in hyponatremia, usually an increase in sodium concentration of more than $18 \mathrm{mg} /$ $\mathrm{dL}$ in the first 48 hours, can be associated with CPM.

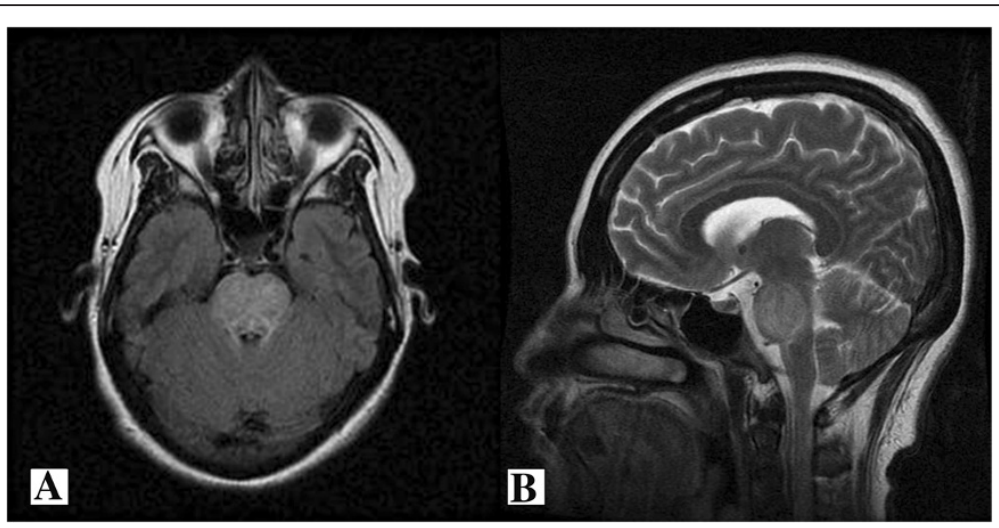

Figure 2 MRI of the brain revealed symmetric, high-intensity signal in the pons with sparing of the peripheral portion, suggesting central pontine myelinolysis ( $A$, axial view and $B$, sagittal view). 
Second, in patients with chronic liver disease and alcoholism, CPM can be associated with acute hypernatremia and hyperglycemia after administration of lactulose for the treatment of hepatic encephalopathy [13]. Third, CPM is associated with acute hypernatremia [3,4] and the rapid correction of hypernatremia $[2,4]$. The relationship between acute hypernatremia and CPM is well characterized in animal experiments, showing acute hypernatremia to result in brain myelinolysis and cellular necrosis [14]. Additionally, animal experiments demonstrated that the osmotic gradient necessary to induce brain myelinolysis is higher for normonatremic than for hyponatremic rats [15]. In our case, an overdose of intravenous sodium bicarbonate was associated with not only acute hypernatremia, but also CPM.

Because there are no proven effective therapies for CPM, its prevention is essential. Supportive therapy should be provided to all patients who were functional prior to the onset of CPM and should be continued for at least six to eight weeks before drawing conclusions about the severity of the deficits and their irreversibility [16]. There have been some animal studies investigating the benefits of re-inducing hyponatremia in the case of rapid overcorrection of hyponatremia in order to avoid osmotic demyelination. Gankam Kengne et al. demonstrated that re-induction of hyponatremia by an intraperitoneal administration of water 12 hours after rapid overcorrection of hyponatremia effectively prevented the opening of the $\mathrm{BBB}$, reduced neurological manifestations, decreased microglial activation, and resulted in a significant decrease in mortality in rats [17]. The rat experiment by Soupart et al. showed that after exposure to an excessive correction of chronic hyponatremia, even when rats have developed myelinolysis-related neurologic symptoms, hypotonic fluids administration could improve survival and could prevent the subsequent development of brain myelinolysis [18].

Although there are no well-studied therapies for CPM, plasma exchange might be a beneficial therapy when CPM is associated with rapid correction of hyponatremia. For example, according to Bibl et al., three young female patients with CPM were successfully treated with extensive therapeutic plasma exchange [5]. These three patients were treated with plasma exchange for three to seven weeks, and their neurological symptoms were improved within two to twelve months. Because undefined myelintoxic compounds released by osmotic stress contribute to the irreversible demyelinating process in CPM, therapeutic plasma exchange may exert its effect by reducing these high-molecular weight myelin-toxic substances, leading to clinical improvement [5]. This theory may explain why plasma exchange was effective in our case of CPM due to acute hypernatremia. Our patient's neurological symptoms, which included dysarthria, difficulty swallowing, and tetraparesis, were markedly improved the day after the two-session regimen of plasma exchange. However, mild diplopia did remain after one year.

Our patient's course supports the concept that intravenous sodium bicarbonate therapy for the treatment of metabolic acidosis can be associated with acute hypernatremia and CPM. In the setting of acute hypernatremia, CPM may be successfully treated with plasma exchange, likely due to the rapid correction of the hyponatremia.

\section{Conclusion}

Our case indicates that serum sodium concentrations should be carefully monitored in patients with distal RTA who are receiving intravenous sodium bicarbonate therapy. We should keep in mind that acute hypernatremia and CPM can be associated with intravenous sodium bicarbonate therapy, and CPM due to acute hypernatremia may be effectively treated with plasma exchange.

\section{Consent}

Written informed consent was obtained from the patient for publication of this Case report and any accompanying images. A copy of the written consent is available for review by the Editor of this journal.

\section{Abbreviations}

ODS: Osmotic demyelination syndrome; CPM: Central pontine myelinolysis; EPM: Extra-pontine myelinolysis; RTA: Renal tubular acidosis;

TTKG: Transtubular potassium gradient; BBB: Blood brain barrier.

\section{Competing interests}

The authors declare that they have no competing interests.

\section{Authors' contributions}

KYC, IHL, GJK, KWC, HSP and HWK treated the patient and provided data about the history and laboratory results in this report. The manuscript was prepared by KYC and HWK. All authors participated in discussions about the manuscript and approved the final version.

\section{Acknowlegements}

The authors would like to thank Young-Soo Kim, MD (Uijeongbu St. Mary's Hospital, The Catholic University of Korea) for helpful comments on the manuscript. This work was not granted or funded by any third party.

Received: 5 November 2013 Accepted: 31 March 2014 Published: 4 April 2014

\section{References}

1. Sterns RH, Cappuccio JD, Silver SM, Cohen EP: Neurologic sequelae after treatment of severe hyponatremia: a multicenter perspective. J Am Soc Nephrol 1994, 4:1522-1530.

2. Go M, Amino A, Shindo K, Tsunoda S, Shiozawa Z: A case of central pontine myelinolysis and extrapontine myelinolysis during rapid correction of hypernatremia. Rinsho Shinkeigaku 1994, 34:1130-1135.

3. Ismail FY, Szollics A, Szolics M, Nagelkerke N, Ljubisavljevic M: Clinical semiology and neuroradiologic correlates of acute hypernatremic osmotic challenge in adults: a literature review. AJNR Am J Neuroradiol 2013: . Epub of ahead.

4. Levin J, Hogen T, Patzig M, Pfister HW, Peters N: Pontine and extrapontine myolinolysis associated with hypernatraemia. Clin Neurol Neurosurg 2012, 114:1290-1291.

5. Bibl D, Lampl C, Gabriel C, Jungling G, Brock H, Kostler G: Treatment of central pontine myelinolysis with therapeutic plasmapheresis. Lancet 1999, 353:1155. 
6. Palmer BF, Alpern RJ: Comprehensive Clinical Nephrology. 4th edition. Philadelphia: Mosby; 2010:155-166.

7. Kim S, Lee JW, Park J, Na KY, Joo KW, Ahn C, Kim S, Lee JS, Kim GH, Kim J, Han JS: The urine-blood PCO gradient as a diagnostic index of $\mathrm{H}(+)$-ATPase defect distal renal tubular acidosis. Kidney Int 2004, 66:761-767.

8. Moder KG, Hurley DL: Fatal hypernatremia from exogenous salt intake: report of a case and review of the literature. Mayo Clin Proc 1990, 65:1587-1594.

9. Sze L, Ulrich B, Brandle M: Severe hypernatraemia due to nephrogenic diabetes insipidus - a life-threatening side effect of chronic lithium therapy. Exp Clin Endocrinol Diabetes 2006, 114:596-598.

10. Anand G, Ali T, Craze J: An unusual case of extreme hypernatraemia. BMJ Case Rep 2009. doi: 10.1136/bcr.03.2009.1697.

11. Imashuku S, Kudo N, Kubo K: Severe hypernatremia and hyperchloremia in an elderly patient with lgG-kappa-type multiple myeloma. J Blood Med 2013, 4:43-47.

12. Adler S, Verbalis JG, Meyers S, Simplaceanu E, Williams DS: Changes in cerebral blood flow and distribution associated with acute increases in plasma sodium and osmolality of chronic hyponatremic rats. Exp Neurol 2000, 163:63-71.

13. Clark WR: Diffuse demyelinating lesions of the brain after the rapid development of hypernatremia. West J Med 1992, 157:571-573.

14. Ayus JC, Armstrong DL, Arieff Al: Effects of hypernatraemia in the central nervous system and its therapy in rats and rabbits. J Physiol 1996, 492(Pt 1):243-255.

15. Soupart A, Penninckx R, Namias B, Stenuit A, Perier O, Decaux G: Brain myelinolysis following hypernatremia in rats. J Neuropathol Exp Neurol 1996, 55:106-113.

16. Sterns RH, Riggs JE, Schochet SS Jr: Osmotic demyelination syndrome following correction of hyponatremia. N Engl J Med 1986, 314:1535-1542.

17. Gankam Kengne F, Soupart A, Pochet R, Brion JP, Decaux G: Re-induction of hyponatremia after rapid overcorrection of hyponatremia reduces mortality in rats. Kidney Int 2009, 76:614-621.

18. Soupart A, Penninckx R, Stenuit A, Perier O, Decaux G: Reinduction of hyponatremia improves survival in rats with myelinolysis-related neurologic symptoms. J Neuropathol Exp Neurol 1996, 55:594-601.

doi:10.1186/1471-2369-15-56

Cite this article as: Chang et al:: Plasma exchange successfully treats central pontine myelinolysis after acute hypernatremia from intravenous sodium bicarbonate therapy. BMC Nephrology 2014 15:56.

\section{Submit your next manuscript to BioMed Central and take full advantage of:}

- Convenient online submission

- Thorough peer review

- No space constraints or color figure charges

- Immediate publication on acceptance

- Inclusion in PubMed, CAS, Scopus and Google Scholar

- Research which is freely available for redistribution 